\title{
Prenatal Visual Exposure to a Predator Influences Lateralization in Goldbelly Topminnows
}

\author{
Marco Dadda 1,*, Veronica Vendramin ${ }^{2}$ and Christian Agrillo 1,3 (D) \\ 1 Department of General Psychology, University of Padova, Via Venezia 8, 35131 Padova, Italy; \\ christian.agrillo@unipd.it \\ 2 CIRVE, University of Padova, Via XXVIII Aprile 14, 31015 Conegliano (TV), Italy; \\ veronica.vendramin@unipd.it \\ 3 Padua Neuroscience Center, University of Padova, Via XXVIII Aprile 14, 31015 Conegliano (TV), Italy \\ * Correspondence: marco.dadda@unipd.it; Tel.: +39-049-8276639; Fax: +39-049-8276600
}

Received: 20 May 2020; Accepted: 20 July 2020; Published: 30 July 2020

\begin{abstract}
The role of genetic and environmental factors in modulating the development of brain lateralization is far from being fully understood, and the presence of individual differences in several lateralized functions is still an open question. In goldbelly topminnows, the genetic basis of asymmetrical functions in the brain has been studied, and recently it has been found that light stimulation influences the expression of lateralization of newborns. Here, we investigated whether prenatal exposure to predators affects the development of lateralization in 10-day-old topminnows born from females exposed to a real or to a simulated predator during pregnancy. Offspring from females exposed to a real predator were lateralized in both visual and motor tests, whereas fish from females exposed to a simulated predator were not and did not differ from controls. Prenatal exposure to a real predator might promote the alignment of lateralization in the same direction in different individuals.
\end{abstract}

Keywords: lateralization; predator; goldbelly topminnows; individual differences; symmetry

\section{Introduction}

Brain lateralization is a common feature among vertebrates and invertebrates [1,2] and is thought to confer some advantages - in particular, the possibility to run multiple tasks in parallel [3,4]. However, behavioral asymmetry has been proved to be disadvantageous as it reduces the integration of the sensory information that reaches the two sides of the brain [5]. Individual variation within and between populations in the degree and the direction of lateralization may be related to the different roles of selective forces acting on this trait [6,7]. Although evidence of a hereditary basis of lateralization has been reported for handedness in non-human primates, for anti-predator behavior in topminnows and in Brachyrhaphis episcopi, and for social behavior in zebrafish [8-10], genetic factors seem to account only partially for individual variation, and an increasing number of studies indicate that the ontogeny of lateralization is influenced by the interaction of genes and experience. Nowadays, it has been shown that several environmental factors interact with genes during development modulating the expression of lateralization [11] such as stress and post-natal handling [12-14], habitat complexity [15], and prenatal exposure to androgens [16,17]. Among these factors, prenatal exposure to light has received particular attention, and its effects have been well documented in birds and fish [18-20]. In birds, according to the asymmetrical positioning of the embryo within the eggshell [21], only the right eye is stimulated by light passing through the shell, whereas the left eye is occluded by the body [18]. In chicks, many behavioral studies reported that this early asymmetric light stimulation later results in lateralized eye use in several contexts including social, spatial, and object recognition tasks [22]. 
In zebrafish, light stimulation penetrates through the transparent eggs during early embryonic stages and influences both neuroanatomical and behavioral asymmetries such as response to social stimuli, exploration of unfamiliar areas, and the tendency to approach potentially dangerous objects $[9,23]$.

Effects of prenatal light exposure have been described also in goldbelly topminnows, Girardinus falcatus, a livebearing fish that has been used in the last decade to investigate the genetic basis of lateralization and the advantages of having a specialized brain [3,8]. Ten-day-old goldbelly topminnows born from females kept at high or low light intensities during pregnancy were later measured for visual and motor lateralization. Fish exposed to high light intensities were lateralized in both tests, whereas fish exposed to low light treatment were not [24].

Exposure to predators is another factor affecting the expression of lateralization [25]. The role of lateralization as a determinant of fish behavior is especially strong within the contexts of predator-prey interactions. Several studies indicate that in vertebrates, anti-predatory behavior is lateralized. Eye preferences in monitoring for predators have been reported for birds, fish, and reptiles [26,27]; increased promptness in recognizing a predator approaching from the left visual field is present in anurans and mammals [28-30], and lateralized fish showed higher escape reactivity compared to poorly-lateralized ones [31]. For the aim of this study, the findings of Brown and colleagues are particularly relevant. They found that in B. episcopi, fish from areas of high- and low-predation pressures differ in their lateralized responses to a live predator, suggesting the role of predation pressure on the development of lateralized behavior patterns [6]. In a subsequent study, Brown and colleagues found that both females and their offspring from high-predation areas showed stronger lateralized behaviour under the scrutiny of a model predator than their counterparts from low-predation areas [32]. Conversely, B. episcopi from high-predation sites take longer to solve a maze task because their laterality hampered their exploratory behavior [33].

The role of predation pressure in modulating the development of lateralization has been described in several studies. Dale Broder and Angeloni [34], using a common garden split-brood design, found that guppies (Poecilia reticulata) exposed to chemical predator cues were more lateralized in a detour test than those reared without predator cues. In the cuttlefish, Sepia officinalis [35], individuals that were exposed to predator odor prior to hatching displayed a left-turning bias in a T-shaped apparatus. Juvenile damselfish (Pomacentrus chrysurus) exposed for 4 days to a high-risk environment became more strongly lateralized than those kept in a low-risk environment [36]. Ferrari and colleagues [37] found that juvenile Ambon damselfish trained to recognize different temporal patterns of risk showed a consistent stronger turning bias. Lucon-Xiccato and colleagues [38] showed that in tadpoles, embryos exposed to risk developed a more frequent clockwise swimming preference than predator-naive controls.

In the present research, we aimed to investigate the effects of visual predator exposure during pregnancy in newborn G. falcatus, a species in which the genetic basis of lateralization and the effects of prenatal light exposure have already been studied [8,24]. To pursue our goal, we present newborns, who were previously exposed to predators during pregnancy, to two different tasks that measure their visual and motor lateralization.

\section{Materials and Methods}

Fish used in this study are lab-reared and have had no previous experience with predators. They originated from stock bought in local pet shops in the 1990s and maintained in a large mixed-sex group ( $>80$ individuals) in 1201 tank. In order to obtain fish developed under different visual stimuli, 30 adult females of the pecilid fish, Girardinus falcatus, were equally divided into three different treatments: real predator (RP), simulated predator (SP), and a control treatment (controls). Females were maintained in 6 glass tanks $(60 \times 40 \times 36 \mathrm{~cm}$, two tanks for each treatment) surrounded with green plastic material (Poliplak) and lit by means of 2 white fluorescent lamps (18W-Sylvania Gro-Lux F18W/GRO IPC code 0000789). Two equally-spaced plastic barriers $(15 \times 40 \mathrm{~cm})$ simulated the plants in the natural environment. These barriers were composed of a series of elongated bars $1 \mathrm{~cm}$ wide and $0.5 \mathrm{~cm}$ apart, virtually dividing the aquarium into three identical sectors. Tanks were provided 
with live plants, gravel on the floor, an air filter, and were filled with $30 \mathrm{~cm}$ of water. Aquaria were maintained at a constant temperature $\left(27 \pm 1^{\circ} \mathrm{C}\right)$ and photoperiod $(0800-2000 \mathrm{~h})$. Fish were fed twice a day (commercial food flakes and Artemia nauplii).

For the RP treatment (Figure 1a), an adult male of Amatitlania nigrofasciata was used (the diet of this cichlid fish includes small fish). The predator was housed in a glass tank $(65 \times 36 \times 65 \mathrm{~cm})$ that was provided with gravel on the floor, an air filter, and a shelter (two plastic jars with a diameter of $16 \mathrm{~cm}$ ). Females were housed in groups of 5 individuals and were exposed to the predator three times a week in three separate sessions of $1 \mathrm{~h}$, each within the same day, and separated by a 3-h inter-trial interval for a total of $9 \mathrm{~h}$ of visual exposure per week. Females lasted in this treatment for 40 days ( 6 weeks). A green plastic partition $(50 \times 35 \mathrm{~cm})$ was removed, allowing for visual contact between the females and the predator. It is worth noting that the subjects in this treatment could see the predator but did not receive any chemosensory information from it.

(a)

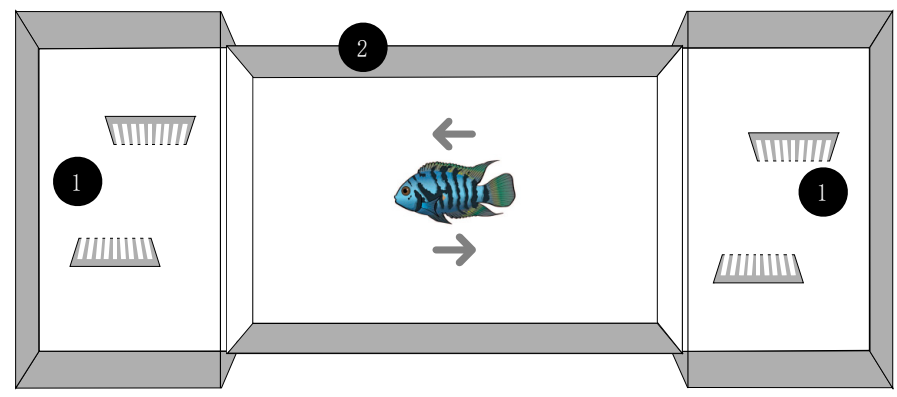

(b)

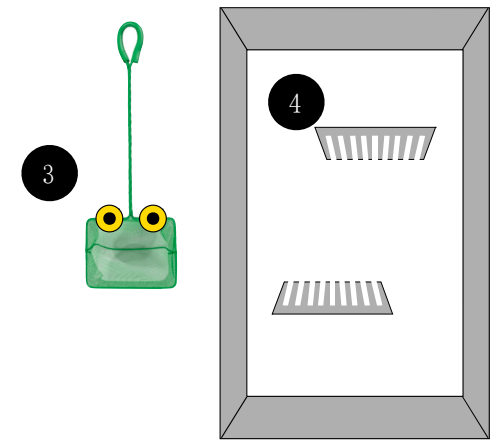

Figure 1. Schematic representation of the apparatuses used for the RP treatment (a) and for the SP treatment (b). (1) Arrangement of the two females' tank for the RP treatment, (2) predator tank, (3) simulated predator, and (4) tank for the SP treatment provided with two plastic barriers.

Simulated predators are commonly used to investigate anti-predatory behavior and escape response instead of real predators mainly because they can be directly inserted into the fish tank without any risk $[38,39]$. We wanted to evaluate whether or not real and simulated predators would affect differently the expression of lateralization. According to this, in the SP treatment (Figure 1b), females were exposed to a simulated predator that consisted of a rectangular $(10 \times 7.5 \mathrm{~cm})$ green net and two yellow discs $(16 \mathrm{~mm} \varnothing)$ with black "pupils" $(6 \mathrm{~mm} \varnothing)$ horizontally arranged in the center as "eyes" [39]. Females were exposed to the simulated predator three times a week in two separate sessions within the same day and separated by a 5-h inter-trial interval for a total of 6 exposure per week. During these sessions, each fish was chased in turn with the simulated predator for at least $20 \mathrm{~s}$ in the tank. Females lasted in this treatment for 40 days ( 6 weeks). The total exposure time was approximately $12 \mathrm{~min}$ per week.

Females of the control treatment were exposed to a replica of the predator tank, but they were not exposed to a real or simulated predator.

Two groups of 5 females for each treatment were used. The females lasted in the treatment for 40 days. Females close to parturition were individually housed into a separate glass tank until birth. All these tanks were equally lit using 2 white fluorescent lamps (15W-Sylvania Gro-Lux F15W/GRO IPC code 0000069). Tanks were checked daily, and once found, the newborns were immediately transferred to smaller glass tanks $(19 \times 30 \times 50 \mathrm{~cm})$ provided with live plants, gravel on the floor, an air filter, and maintained at a controlled temperature $\left(27 \pm 1^{\circ} \mathrm{C}\right)$, and a photoperiod of $(0800-2000 \mathrm{~h})$. Newborns were housed in these tanks for a period of 10 days. At the end of this period, the newborns were observed in two tests that measure visual and motor lateralization. We tested 84 10-day-old 
topminnows, 28 born from each of the three treatments. Forty-four subjects were tested in the mirror test, and the remaining forty in the rotational preference test.

To prevent that the majority of the fry from originating from a single female, each female contributed a maximum of three fry to the sample.

Ethics Statement:

This study was performed in accordance with the recommendations of law (Italy, D.L. 4 Marzo 2014, n. 26). The protocol has been approved by the Ethical Committee of Università di Padova (protocol n. 32/2015).

\subsection{Mirror Test}

Forty-four subjects (14 RP, $15 \mathrm{SP}$, and 15 control) were observed in this test. We employed the same apparatus used by Dadda and Bisazza that consisted of a small aquarium $(20 \times 20 \times 25 \mathrm{~cm})$ surrounded with eight mirrors $(5.5 \times 8 \mathrm{~cm})$ placed around the aquarium's walls. A hollow transparent cylinder was placed at the center of the apparatus. Using a nylon thread, the cylinder could be lifted, allowing the fish to explore the new environment. The apparatus was lit by 4 white fluorescent lamps (8W-Sylvania Gro-Lux F8W/GRO IPC code 0000026) and filled with $4 \mathrm{~cm}$ of water. A video camera was mounted above the apparatus at a distance of $1 \mathrm{~m}$.

Each subject was captured from his home tank, transported to the apparatus, and gently released into the cylinder. After a 2-min period, the cylinder was raised and the subject's swimming behavior was recorded for a period of $10 \mathrm{~min}$. At the end of the observation, the subject was released back to his home tank. Each subject was tested once.

Video recordings were analyzed using a specific computer program (Ciclic Timer Version 1.3). The laterality index was calculated considering the proportion of left eye use while swimming with their mirror image. We scored the observations in which the fish was swimming alongside a mirror for a maximum distance of $3.5 \mathrm{~cm}$. Observations made while the subject was perpendicular to the mirror were discarded.

\subsection{Rotational Preference in a Familiar Environment}

Forty subjects (14 RP, $13 \mathrm{SP}$, and 13 control) were observed in this test. We employed the same apparatus used by Dadda and Bisazza [25] that consisted of a ring-shaped swimway made of green plastic material (height $4 \mathrm{~cm}$, inner radius $5 \mathrm{~cm}$, outer radius $10 \mathrm{~cm}$ ) and filled with $3 \mathrm{~cm}$ of water. Each fish was housed individually in a swimway. A video camera was positioned approximately $1 \mathrm{~m}$ above the apparatus. The camera recorded four adjacent swimways. Each fish was placed into the apparatus at 12:00 a.m. and left undisturbed until 10:00 a.m. the next day. The subject's behavior was then recorded for $1 \mathrm{~h}$. The apparatus was lit by 4 white fluorescent lamps (8W-Sylvania Gro-Lux F8W/GRO IPC code 0000026) connected to a timer (8:00 a.m. to 20:00 p.m. L-D cycle). Lateral asymmetries were scored from video recordings by calculating for each subject the proportion of counter-clockwise rotations.

Statistics were conducted using SPSS 25. In all ANOVAs, we checked for normality and homogeneity of variance, and when required, appropriate transformation of the data was performed. All probabilities are two-tailed.

\section{Results}

\subsection{Mirror Test}

The laterality index was analyzed with one-way ANOVA and one-sample $t$ tests. Subjects from the three treatments did not differ significantly in the total time spent shoaling with their mirror image (mean \pm SD—RP: $531.78 \pm 43.53$; SP: $525.20 \pm 56.24$; controls: $534.80 \pm 52.48 ; \mathrm{F}(2,43)=0.138$, $p=0.872)$. Subjects from the three treatments differ significantly in their eye preference $(\mathrm{F}(2,43)=5.943$, $p=0.005$, Figure 2a). RP subjects showed a significant left-eye preference (one sample $t$-test, 
$t(13)=4.471, p<0.001)$, whereas SP and control subjects did not show asymmetries in eye preference $(t(14)=0.324, p=0.751$ and $t(14)=0.294, p<0.773$ for SP and controls, respectively $)$.

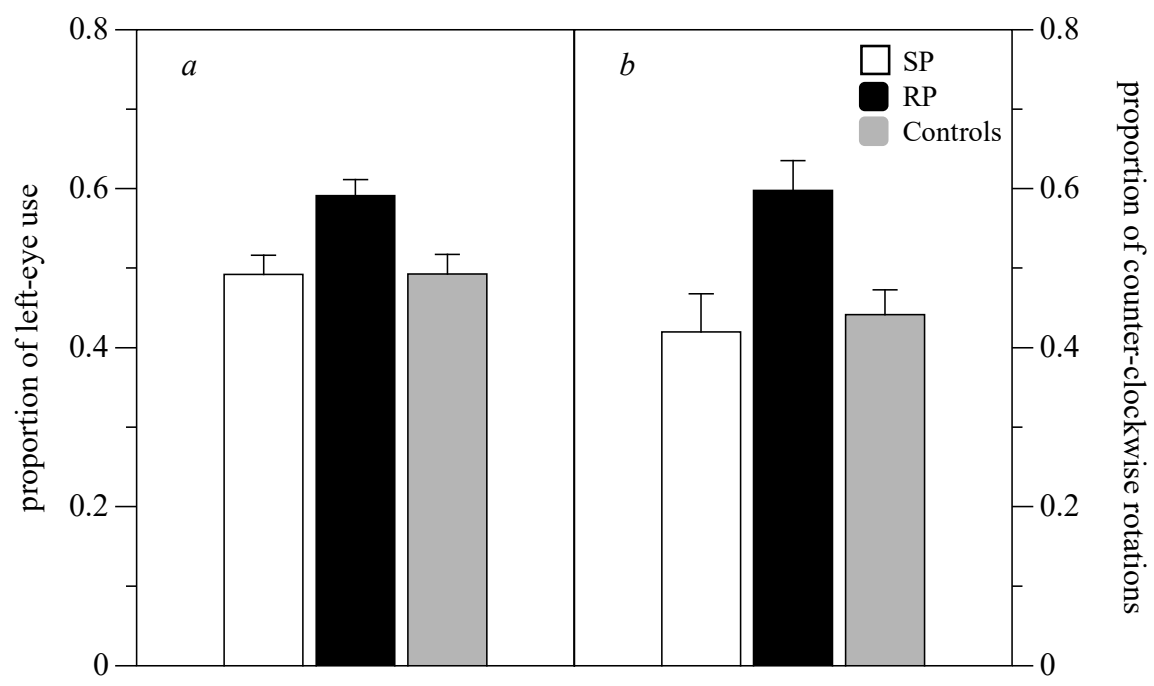

Figure 2. The proportion of left eye use while shoaling with the mirror image (a). The proportion of counterclockwise rotations in the home tank (b).

Considering the absolute index of laterality (0.5-|laterality index|), which supplies a measure of the strength of lateralization irrespective from its direction, the three groups of fish did not differ significantly (RP: $0.077 \pm 0.042$; SP: $0.104 \pm 0.059$; controls: $0.086 \pm 0.044 ; \mathrm{F}(2,43)=1.102, p=0.342$ ).

We checked for possible differences between the three groups during the $10 \mathrm{~min}$ of observation using repeated measures ANOVA where the minute of the test was the "within-subjects" factor while treatment was the "between subjects" factor. The laterality index was the dependent variable. Subjects' behavior did not change significantly during the test $(\mathrm{F}(9,369)=1.106, p=0.358$, Figure 3$)$ while the effect of treatment was significant $(\mathrm{F}(2,41)=5.255, p=0.009)$.

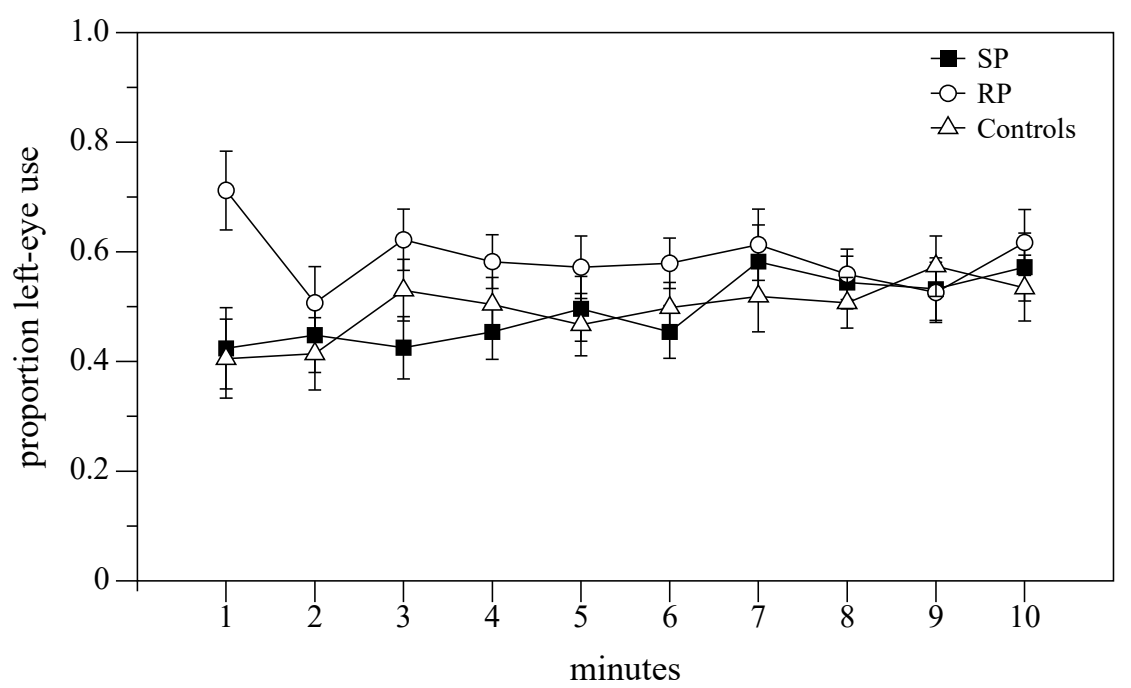

Figure 3. The proportion of left eye use in the mirror test during the ten minutes of observation.

\subsection{Rotational Preference in a Familiar Environment}

The laterality index was analyzed using one-way ANOVA and one-sample t-tests. Subjects from RP, SP, and control treatments did not differ significantly in the total time spent swimming (RP: $1421.50 \pm 801.50 ;$ SP: $1355.72 \pm 770.59$; controls: $1454 \pm 780.27 ; \mathrm{F}(2,38)=0.031, p=0.749)$. 
Subjects from the three treatments differed significantly in their rotational preference $(F(2,38)=5.088, p=0.011$, Figure $2 b) . R P$ subjects showed a significant preference for counter-clockwise rotations $(t(13)=2.582, p=0.026)$, whereas SP and control subjects did not show asymmetries in eye preference $(t(12)=1.873, p=0.091 ; t(12)=1.678, p=0.116$ for SP and controls, respectively).

Considering the absolute index of laterality, the three groups of fish did not differ significantly (RP: $0.098 \pm 0.063 ;$ SP: $0.104 \pm 0.12$; controls: $0.015 \pm 0.13 ; \mathrm{F}(2,38)=1.221, p=0.307$ ).

\section{Discussion}

The present study aimed to evaluate the role of predator exposure during pregnancy in modulating the expression and development of lateralization. Results showed that this environmental factor appears to influence lateralization in goldbelly topminnows. To our knowledge, this is the first evidence of the effects of visual predator exposure during pregnancy in newborns of poecilid fish. The three treatments differed significantly for both visual and motor tasks, but only when the measures of laterality were considered. Subjects from the RP showed evidence of lateralized behavior in both the mirror (with a preference for the left eye) and in the rotational test in a familiar environment (with a preference for counterclockwise rotation), while those from the SP treatment and the control group did not. Although the laterality index in the mirror test did not change significantly during the test, the difference between the three groups appears to decrease with time. As reported elsewhere [40], it is likely that habituation to the novel social stimulus occurred after the first few minutes. On the other hand, no difference was present regarding the total time spent shoaling or the number of rotations.

Our results are consistent with the findings of Dadda and Bisazza [24], who observed that ten-day-old topminnows born from females kept at high light intensities during pregnancy were significantly lateralized in visual and motor tests compared to their counterparts exposed to low light intensities. Specifically, light exposure apparently contributes to the alignment of lateralization at the population level. This seems to be true also in the present research; females exposed to a real predator determined the alignment of the direction of lateralization in most individuals of their progeny (left-eye use in shoaling and counterclockwise rotation) although the strength of lateral biases appears to be unaffected. This is also consistent with previous studies on zebrafish and chicks where light/dark incubation of embryos and the amount of light that enters through the eggshell influence many aspects of lateralization $[19,25,41]$. Predation pressure is confirmed to play a crucial role in the development of lateralized behavior consistently to previous findings in fish $[6,32,33]$. Even without other concurrent cues, prenatal visual exposure to a real predator influences the fry's visual and motor lateralization. Our results, however, indicate that only the exposure to a real predator is effective, while the simulated predator apparently does not affect significantly a fry's laterality. There are several possible interpretations of this finding. Simulated predators, usually fish lures, proved to be valid $[39,40,42]$ in several fish studies, while here we used a modified net already adopted in a previous study but for a different purpose. One of the weaknesses of this study is that we cannot exclude that in this context this particular version was not effective. Even more importantly, the RP and SP treatments differ greatly in the total duration of exposure to the stimulus; prolonged exposure to the real predator is not counterbalanced by the shorter exposure to the simulated predator. This was mainly due to the fact that prolonged exposure to the chasing simulated predator would have excessively increased the perceived stress in females. Better management of the exposure times to the two stimuli could help clarify the differences between these two treatments.

Predator exposure might act in G. falcatus by influencing the mother's physiology, considering that variable levels of steroid hormones to which the embryo is exposed affect the lateralization of the progeny $[43,44]$. In birds and mammals, maternal steroid hormones (glucocorticoids and androgens) represent a relevant factor affecting the development of lateralization [45]. In fish, elevated levels of maternal stress hormones are known to influence several aspects of fry development [46]. Schaafsma and Groothuis showed that prenatal exposure to different levels of testosterone changed the direction of lateralization while inspecting a predator only in female cichlid fish Aequidens rivulatus but did 
not have an effect on the rotational preference while viewing their mirror image as a stimulus [47]. Therefore, one would expect that also in the SP treatment, net chasing could have increased the female's stress level. In fact, net chasing increases cortisol levels, which reflect a high-stress condition in fish [48]. Moreover, in the literature, there is evidence that repeated net chasing in their familiar environment can alter behavior in fish species, including B. episcopi, Pagrus major, guppies, and A. nigrofasciata [33,49-51]. Interestingly Brown and colleagues [33] showed that fish chased by a net for $2 \mathrm{~min}$ a day for 2 weeks became bolder than those left undisturbed. A relationship between stress and boldness has been documented in several fish species; bolder fish show lower ventilation rates and lower release rates of cortisol [52,53]. According to this one cannot completely rule out the possibility that being exposed to a real predator instead of being chased by a net would have affected differently stress responsiveness in our females. A comparison of cortisol concentration for both treatments is necessary to properly answer this question, especially considering that exposure to cortisol is directly involved in increasing the strength of lateralization [37]. The use of a simulated predator that is chasing the subjects is still questionable also because it introduces a confounding variable (visual stimulation and physical exertion) with respect to the RP treatment. Having said this, a static-simulated predator presented several times would rapidly turn into a neutral stimulus, thereby defeating its own purpose.

There are other examples in which the effects of predator exposure are independent of stress hormones. In Daphnia pulex it has been shown that the detection of chemical cues released by a predator affects Daphnia's swimming patterns and morphology by developing neck teeth, heavier carapaces, and long head spines to reduce their susceptibility to predation [54]. Chivers and colleagues [55] showed that, when exposed to predation cues, goldfish increased their depth and weight faster than goldfish exposed to water without cues. When reared in the presence of a caged larvivorous-fish (Gambusia affinis), mosquito larvae (Culex pipiens) reduce their development time and increase their body size [56]. On the contrary, Monteforte and colleagues [42] showed that in guppies, maternal exposure to predation risk did not affect significantly telomere (nucleoprotein complexes susceptible to stress exposure) length in both adult females and in their offspring. However, subjects exposed to predation risk produced smaller offspring at birth. All these findings indicate that predator pressure might act at different levels in shaping morphology and/or in affecting the mother's physiology. A deeper approach would consider both these aspects to better estimate the effects of predator pressure on the expression of lateralization.

To date, a clear demonstration of the possible role of predation pressure during development in modulating lateralization comes from a rather small number of studies. Jozet-Alves and Hebert [35] revealed that cuttlefish embryos exposed to predator odor are more likely to turn to the left in a T-shaped apparatus. As suggested by the authors, the biases observed may be a reflection of both the neurobiological and the psychological impacts of predator exposure during embryonic development. Ferrari and colleagues [36] indicate how early exposure to differential predation risk influences the degree of lateralization in fish, suggesting that the expression of lateralization can be modulated; subjects were more strongly lateralized at the time when the perceived risk was highest compared to when the risk perceived was reduced [57]. The advantages of developing as a strongly lateralized individual in a high predation risk context are supported by the study of Lucon-Xiccato and colleagues [37], where lateralization increases cognitive abilities directly associated with predator defense. It would be also interesting to investigate how predation pressure might act on the relationship between lateralization and aggressive behavior in terms of prey-predator interaction [58,59].

It is likely that predation pressure and light responsiveness may be part of the same mechanism [25]. For example, predation pressure might act on the amount of light that reaches the embryos by influencing the mother's behavior, modulating the development of lateralization. The fact that environmental cues, such as an abundance of predators, encourage the alignment of lateralization at the population level might be explained by Vallortigara and Rogers [25]. The authors suggest that it is occasionally better for an individual to do what the other individuals in the group are doing, thus increasing coordination. For example, when chased by a predator, it would be beneficial for each fish to align the direction 
of escape responses with that of the other individuals of the group [25]. Note, however, that Bibost and Brown [15] have also suggested that shoals composed of mixed lateralized individuals might be more effective at predator avoidance. Finally, it is worth noting that predator pressure can vary enormously in different habitats for the same species $[60,61]$ and the costs and benefits associated with population-level lateralization of anti-predator behavior may also differ significantly.

To summarize, this study provides further evidence that a mother experiencing stressful situations can adaptively modulate the development of laterality in their offspring [62,63]. Although the mechanisms that connect predation pressure to the laterality of the progeny are far from being completely understood, the mere visual exposure to a real predator is among those maternal effects (e.g., androgens exposure, features of the rearing environment) that influence the development of lateralization and may represent an adaptive response to the environmental requests. In other words, to ensure that their progeny would better cope with current conditions, mothers exposed to a real predator adjust the developmental trajectories of their offspring accordingly $[19,62]$.

Author Contributions: Conceptualization: M.D.; Methodology: M.D., and V.V.; Data collection: V.V.; Writing: M.D. and C.A. All authors have read and agree to the published version of the manuscript.

Funding: This study was supported by 'DOR' grant from the University of Padova to M.D.

Conflicts of Interest: The authors declare no conflict of interest.

\section{References}

1. Frasnelli, E.; Vallortigara, G.; Rogers, L.J. Left-right asymmetries of behaviour and nervous system in invertebrates. Neurosci. Biobehav. Rev. 2012, 36, 1273-1291. [CrossRef] [PubMed]

2. Rogers, L.J. Lateralization in its many forms, and its evolution and development. Spec. Top. Primatol. 2007, 5, 22-56.

3. Dadda, M.; Bisazza, A. Does brain asymmetry allow efficient performance of simultaneous tasks? Anim. Behav. 2006, 72, 523-529. [CrossRef]

4. Rogers, L.J.; Zucca, P.; Vallortigara, G. Advantages of having a lateralized brain. Proc. R. Soc. B Biol. Sci. 2004, 271, S420-S422. [CrossRef]

5. Dadda, M.; Zandonà, E.; Agrillo, C.; Bisazza, A. The costs of hemispheric specialization in a fish. Proc. R. Soc. B Biol. Sci. 2009, 276, 4399-4407. [CrossRef]

6. Brown, C.; Gardner, C.; Braithwaite, V.A. Population variation in lateralized eye use in the poeciliid Brachyraphis episcopi. Proc. R. Soc. B Biol. Sci. 2004, 271, S455-S457. [CrossRef]

7. Ghirlanda, S.; Vallortigara, G. The evolution of brain lateralization: A game-theoretical analysis of population structure. Proc. R. Soc. B Biol. Sci. 2004, 271, 853-857. [CrossRef]

8. Bisazza, A.; Dadda, M.; Facchin, L.; Vigo, F. Artificial selection on laterality in the teleost fish. Behav. Brain Res. 2007, 178, 29-38. [CrossRef]

9. Dadda, M.; Domenichini, A.; Piffer, L.; Argenton, F.; Bisazza, A. Early differences in epithalamic left-right asymmetry influence lateralization and personality of adult zebrafish. Behav. Brain Res. 2010, 206, 208-215. [CrossRef]

10. Hopkins, W.D.; Dahl, J.F.; Pilcher, D. Genetic influence on the expression of hand preferences in Chimpanzees (Pan troglodytes): Evidence in Support of the Right-Shift Theory and Developmental Instability. Psychol. Sci. 2001, 12, 299-303. [CrossRef]

11. Vallortigara, G.; Versace, E. Laterality at the Neural, Cognitive, and Behavioral Levels. In APA Handbook of Comparative Psychology: Basic Concepts, Methods, Neural Substrate, and Behavior; Call, J., Burghardt, G., Pepperberg, I.M., Snowdon, C.T., Zentall, T., Eds.; American Psychological Association: Washington, DC, USA, 2017; Volume 1, pp. 557-577.

12. Cowell, P.; Waters, N.; Denenberg, V. The effects of early environment on the development of functional laterality in Morris maze performance. Laterality Asymmetries Body Brain Cogn. 1997, 2, 221-232. [CrossRef] [PubMed] 
13. Gadea, M.; Gomez, C.; González-Bono, E.; Salvador, A.; Espert, R. Salivary testosterone is related to both handedness and degree of linguistic lateralization in normal women. Psychoneuroendocrinology 2003, 28, 274-287. [CrossRef]

14. Williams, H.; Crane, L.A.; Hale, T.K.; Esposito, M.A.; Nottebohm, F. Right-side dominance for song control in the zebra finch. J. Neurobiol. 1992, 23, 1006-1020. [CrossRef]

15. Bibost, A.-L.; Kydd, E.; Brown, C. The Effect of Sex and Early Environment on the Lateralization of the Rainbowfish Melanotaenia duboulayi. In Behavioral Lateralization in Vertebrates: Two Sides of the Same Coin; Csermely, D., Regolin, L., Eds.; Springer: Berlin/Heidelberg, Germany, 2013; pp. 9-24. [CrossRef]

16. Pfannkuche, K.A.; Bouma, A.; Groothuis, T.G. Does testosterone affect lateralization of brain and behaviour? A meta-analysis in humans and other animal species. Philos. Trans. R. Soc. B Boil. Sci. 2009, 364, 929-942. [CrossRef] [PubMed]

17. Schaafsma, S.M.; Groothuis, T.G. Sex-specific effects of postnatal testosterone on lateralization in cichlid fish. Anim. Behav. 2011, 81, 283-288. [CrossRef]

18. Rogers, L.J. Light input and the reversal of functional lateralization in the chicken brain. Behav. Brain Res. 1990, 38, 211-221. [CrossRef]

19. Andrew, R.J.; Osorio, D.; Budaev, S. Light during embryonic development modulates patterns of lateralization strongly and similarly in both zebrafish and chick. Philos. Trans. R. Soc. B Boil. Sci. 2009, 364, 983-989. [CrossRef]

20. Casey, M.B.; Sleigh, M.J. Prenatal visual experience induces postnatal motor laterality in japanese quail chicks (Coturnix coturnix japonica). Dev. Psychobiol. 2013, 56, 489-497. [CrossRef]

21. Manns, M.; Ströckens, F. Functional and structural comparison of visual lateralization in birds-similar but still different. Front. Psychol. 2014, 5, 206. [CrossRef]

22. Güntürkün, O.; Ocklenburg, S. Ontogenesis of lateralization. Neuron 2017, 94, 249-263. [CrossRef]

23. Budaev, S.; Andrew, R.J. Patterns of early embryonic light exposure determine behavioural asymmetries in zebrafish: A habenular hypothesis. Behav. Brain Res. 2009, 200, 91-94. [CrossRef] [PubMed]

24. Dadda, M.; Bisazza, A. Prenatal light exposure affects development of behavioural lateralization in a livebearing fish. Behav. Process. 2012, 91, 115-118. [CrossRef] [PubMed]

25. Vallortigara, G.; Rogers, L.J. Survival with an asymmetrical brain: Advantages and disadvantages of cerebral lateralization. Behav. Brain Sci. 2005, 28, 575-589. [CrossRef] [PubMed]

26. Koboroff, A.; Kaplan, G.; Rogers, L.J. Hemispheric specialization in Australian magpies (Gymnorhina tibicen) shown as eye preferences during response to a predator. Brain Res. Bull. 2008, 76, 304-306. [CrossRef]

27. Martín, J.; López, P.; Bonati, B.; Csermely, D. Lateralization when monitoring predators in the wild: A left eye control in the common wall lizard (Podarcis muralis). Ethology 2010, 116, 1226-1233. [CrossRef]

28. Lippolis, G.; Westman, W.; McAllan, B.; Rogers, L. Lateralisation of escape responses in the stripe-faced dunnart, Sminthopsis macroura (Dasyuridae: Marsupialia). Laterality 2005, 10, 457-470. [CrossRef]

29. Siniscalchi, M.; Bertino, D.; Quaranta, A. Laterality and performance of agility-trained dogs. Laterality Asymmetries Body Brain Cogn. 2014, 19, 219-234. [CrossRef]

30. Shibasaki, M.; Nagumo, S.; Koda, H. Japanese monkeys (Macaca fuscata) spontaneously associate alarm calls with snakes appearing in the left visual field. J. Comp. Psychol. 2014, 128, 332. [CrossRef]

31. Domenici, P.; Allan, B.; McCormick, M.I.; Munday, P.L. Elevated carbon dioxide affects behavioural lateralization in a coral reef fish. Boil. Lett. 2012, 8, 78-81. [CrossRef]

32. Brown, C.; Western, J.; Braithwaite, V.A. The influence of early experience on, and inheritance of, cerebral lateralization. Anim. Behav. 2007, 74, 231-238. [CrossRef]

33. Brown, C.; Braithwaite, V.A. Effects of predation pressure on the cognitive ability of the poeciliid Brachyraphis episcopi. Behav. Ecol. 2004, 16, 482-487. [CrossRef]

34. Dale Broder, E.; Angeloni, L.M. Predator-induced phenotypic plasticity of laterality. Anim. Behav. 2014, 98, 125-130. [CrossRef]

35. Jozet-Alves, C.; Hébert, M. Embryonic exposure to predator odour modulates visual lateralization in cuttlefish. Proc. R. Soc. B Biol. Sci. 2013, 280, 1752. [CrossRef]

36. Ferrari, M.C.; McCormick, M.I.; Meekan, M.G.; Chivers, D.P. Background level of risk and the survival of predator-naive prey: Can neophobia compensate for predator naivety in juvenile coral reef fishes? Proc. $R$. Soc. B Biol. Sci. 2015, 282, 20142197. [CrossRef] 
37. Lucon-Xiccato, T.; Chivers, D.P.; Mitchell, M.D.; Ferrari, M.C. Prenatal exposure to predation affects predator recognition learning via lateralization plasticity. Behav. Ecol. 2016, 28, arw155. [CrossRef]

38. Bisazza, A.; Pignatti, R.; Vallortigara, G. Detour tests reveal task- and stimulus-specific behavioural lateralization in mosquitofish (Gambusia holbrooki). Behav. Brain Res. 1997, 89, 237-242. [CrossRef]

39. Bisazza, A.; Cantalupo, C.; Capocchiano, M.; Vallortigara, G. Population lateralisation and social behaviour: A study with 16 species of fish. Laterality 2000, 5, 269-284. [CrossRef]

40. Sovrano, V.A.; Bisazza, A.; Vallortigara, G. Lateralization of response to social stimuli in fishes: A comparison between different methods and species. Physiol. Behav. 2001, 74, 237-244. [CrossRef]

41. Chiandetti, C. Manipulation of strength of cerebral lateralization via embryonic light stimulation in birds. In Lateralized Brain Functions; Springer: Berlin, Germany, 2017; pp. 611-631.

42. Monteforte, S.; Cattelan, S.; Morosinotto, C.; Pilastro, A.; Grapputo, A. Maternal predator-exposure affects offspring size at birth but not telomere length in a live-bearing fish. Ecol. Evol. 2020, 10, 2030-2039. [CrossRef]

43. Rogers, L.J.; Deng, C. Corticosterone treatment of the chick embryo affects light-stimulated development of the thalamofugal visual pathway. Behav. Brain Res. 2005, 159, 63-71. [CrossRef]

44. Rougeot, C.; Krim, A.; Mandiki, S.N.M.; Kestemont, P.; Melard, C. Sex steroid dynamics during embryogenesis and sexual differentiation in Eurasian perch, Perca fluviatilis. Theriogenology 2007, 67, 1046-1052. [CrossRef] [PubMed]

45. Bisazza, A.; Brown, C. Lateralization of Cognitive Functions in Fish. In Fish Cognition and Behavior; Brown, C., Laland, K., Krause, J., Eds.; Wiley-Blackwell, Wiley: Chichester, UK; Ames, IA, USA, 2011; pp. 298-324. [CrossRef]

46. McCormick, M.I. Behaviorally induced maternal stress in a fish influences progeny quality by a hormonal mechanism. Ecology 1998, 79, 1873-1883. [CrossRef]

47. Schaafsma, S.M.; Groothuis, T.G. Sex-specific effects of maternal testosterone on lateralization in a cichlid fish. Anim. Behav. 2012, 83, 437-443. [CrossRef]

48. Barcellos, L.J.G.; Volpato, G.L.; Barreto, R.E.; Coldebella, I.; Ferreira, D. Chemical communication of handling stress in fish. Physiol. Behav. 2011, 103, 372-375. [CrossRef] [PubMed]

49. Takahashi, K.; Masuda, R. Net-chasing training improves the behavioral characteristics of hatchery-reared red sea bream (Pagrus major) juveniles. Can. J. Fish. Aquat. Sci. 2018, 75, 861-867. [CrossRef]

50. Smith, B.R.; Blumstein, D.T. Structural consistency of behavioural syndromes: Does predator training lead to multi-contextual behavioural change? Behaviour 2012, 149, 187-213. [CrossRef]

51. Moscicki, M.K.; Hurd, P.L. Sex, boldness and stress experience affect convict cichlid, Amatitlania nigrofasciata, open field behaviour. Anim. Behav. 2015, 107, 105-114. [CrossRef]

52. Brown, C.; Jones, F.; Braithwaite, V. In situ examination of boldness-shyness traits in the tropical poeciliid, Brachyraphis episcopi. Anim. Behav. 2005, 70, 1003-1009. [CrossRef]

53. Brown, C.; Gardner, C.; Braithwaite, V.A. Differential stress responses in fish from areas of high-and low-predation pressure. J. Comp. Physiol. B 2005, 175, 305-312. [CrossRef]

54. Peñalva-Arana, D.C.; Lynch, M.; Robertson, H.M. The chemoreceptor genes of the waterflea Daphnia pulex: Many Grs but no Ors. BMC Evol. Boil. 2009, 9, 79. [CrossRef]

55. Chivers, D.P.; Zhao, X.; Brown, G.E.; Marchant, T.A.; Ferrari, M.C. Predator-induced changes in morphology of a prey fish: The effects of food level and temporal frequency of predation risk. Evol. Ecol. 2008, 22, 561-574. [CrossRef]

56. Alcalay, Y.; Puzhevsky, D.; Tsurim, I.; Scharf, I.; Ovadia, O. Interactive and sex-specific life-history responses of Culex pipiens mosquito larvae to multiple environmental factors. J. Zool. 2018, 306, 268-278. [CrossRef]

57. Ferrari, M.C.; McCormick, M.I.; Mitchell, M.D.; Allan, B.J.; Gonçalves, E.J.; Chivers, D.P. Daily variation in behavioural lateralization is linked to predation stress in a coral reef fish. Anim. Behav. 2017, 133, 189-193. [CrossRef]

58. Siniscalchi, M.; Bertino, D.; d'Ingeo, S.; Quaranta, A. Relationship between Motor Laterality and Aggressive Behavior in Sheepdogs. Symmetry 2019, 11, 233. [CrossRef]

59. Siniscalchi, M.; d'Ingeo, S.; Quaranta, A. Lateralized functions in the dog brain. Symmetry 2017, 9, 71. [CrossRef]

60. Bell, A.M.; Sih, A. Exposure to predation generates personality in threespined sticklebacks (Gasterosteus aculeatus). Ecol. Lett. 2007, 10, 828-834. [CrossRef] 
61. Dingemanse, N.J.; Wright, J.; Kazem, A.J.; Thomas, D.K.; Hickling, R.; Dawnay, N. Behavioural syndromes differ predictably between 12 populations of three-spined stickleback. J. Anim. Ecol. 2007, 76, 1128-1138. [CrossRef]

62. Deng, C.; Rogers, L.J. Factors affecting the development of lateralization in chicks. In Comparative Vertebrate Lateralization; Cambridge University Press: Cambridge, UK, 2002; pp. 206-246.

63. Halpern, M.E.; Güntürkün, O.; Hopkins, W.D.; Rogers, L.J. Lateralization of the vertebrate brain: Taking the side of model systems. J. Neurosci. 2005, 25, 10351-10357. [CrossRef]

(C) 2020 by the authors. Licensee MDPI, Basel, Switzerland. This article is an open access article distributed under the terms and conditions of the Creative Commons Attribution (CC BY) license (http://creativecommons.org/licenses/by/4.0/). 